This item was submitted to Loughborough's Research Repository by the author.

Items in Figshare are protected by copyright, with all rights reserved, unless otherwise indicated.

\title{
Physically fit or physically literate? How children with special educational needs understand physical education
}

PLEASE CITE THE PUBLISHED VERSION

http://dx.doi.org/10.1177/1356336X11413183

\section{PUBLISHER}

(c) The Authors. Published by SAGE Publications (UK and US)

\section{VERSION}

AM (Accepted Manuscript)

\section{PUBLISHER STATEMENT}

This work is made available according to the conditions of the Creative Commons Attribution-NonCommercialNoDerivatives 4.0 International (CC BY-NC-ND 4.0) licence. Full details of this licence are available at: https://creativecommons.org/licenses/by-nc-nd/4.0/

\section{LICENCE}

CC BY-NC-ND 4.0

\section{REPOSITORY RECORD}

Coates, Janine. 2019. "Physically Fit or Physically Literate? How Children with Special Educational Needs Understand Physical Education”. figshare. https://hdl.handle.net/2134/25021. 
Physically Fit or Physically Literate?

Children with Special Educational Needs Understanding of Physical Education

Date submitted: 08/03/2011

Word Count: 6694

Dr Janine Coates

University of Nottingham

School of Community Health Sciences, Department of Developmental Psychiatry

Sir Colin Campbell Building

Jubilee Campus

Triumph Road

Nottingham

NG8 1BB

01158232458

Janine.Coates@nottingham.ac.uk

\section{Biographical note:}

Dr Janine Coates is a research fellow at the University of Nottingham in the School of Community Health Sciences. She has recently completed her PhD at Liverpool John Moores University, which examined pupil voice in children with Special Educational Needs in Physical Education. 


\section{Abstract}

The role of physical literacy within physical education (PE) has become a widely debated topic in recent years. Its role in educating children about physicality through embodiment, skill acquisition and reading the environment is argued to be of great benefit to children. However, whether children understand the role of PE in the development of these competencies is not clear, and this is even truer for children who have special educational needs (SEN). Drawing on qualitative phenomenological data from 30 children in key stages 2 and three ( 7 to 14 years of age) who have SEN, this paper explores notions of physical fitness and physical literacy as understood by children in PE lessons. It aims to gain insight into the ways that children understand the purpose of $\mathrm{PE}$, and places these perceptions within a physical literacy framework, using the National Curriculum for PE (NCPE) as a foundation. Findings demonstrate that children with SEN perceive PE as a means for improving physical fitness, whereas concepts surrounding physical literacy appear to be lost. The paper concludes by making recommendations for factoring physical literacy components more forcibly into the PE curriculum, and through initial teacher training and continued professional development.

Key words: Children, Curriculum, Fitness, Physical Literacy, Special Educational Needs 


\section{Introduction}

This paper reports on some of the findings from a larger research study which sought to examine the perceptions and experiences of children with Special Educational Needs (SEN) in Physical Education (PE). In particular, it examines children with SEN's conceptions of the meaning and purpose of $\mathrm{PE}$, which was identified as one of the core themes within the research.

This paper therefore presents a discussion which facilitates children with SEN's knowledge and understanding surrounding the reasons why they participate in PE at school. It is argued that by acknowledging the ways in which children with SEN's perceptions surrounding the purpose of $\mathrm{PE}$, more insight can be given to the ways in which they experience PE lessons, and their wider perceptions relating to physical activity in the life term. Moreover, it provides a platform for an evaluation surrounding the ways in which the PE curriculum is delivered, and presents the argument that an overemphasis of physical fitness notions, over physical literacy, can be detrimental to the ways in which children with SEN experience PE (Evans, 2004). In terms of this, a physically literate individual is one who embodies the physical nature of movement and uses their experiences and knowledge to interact with the environment (Whitehead, 2001; Whitehead and Murdoch, 2006). Physical literacy is about educating individuals about their physicality, which does not only pertain to 'being physical', but encapsulates an embodied understanding about how to be physical by interacting with varied and challenging environments (Whitehead, 2001; Whitehead and Murdoch, 2006; Killingbeck et al, 2007). Physical fitness on the other hand, refers to the use of physical activity as a means of maintaining or improving the physical wellness through exercise (Evans, 2004). 


\section{The National Curriculum for PE: What are teachers teaching?}

This study examined the perceptions of children with SEN in both primary (Key Stage (KS) 2) and secondary education (KS3). While there are differences in the National Curriculum for PE (NCPE) for both KS2 and KS3 (Department for Education and Skills (DfES)/Qualifications and Curriculum Agency (QCA), 1999; QCA, 2007), the over-arching outcomes of PE regardless of key stage are to develop physically literate children - the notion that PE provides opportunity for children to master the skills of movement, reading the environment and responding to it effectively (Whitehead, 2001, 2005), whilst developing their understanding about physical fitness and lifelong physical activity (DfES/ QCA, 1999; QCA, 2007). Physical education therefore pertains to physical literacy. For children, and appreciation of becoming physically literate might come in the form of understanding the skills required to perform a specific task, or by assessing the environment, and demonstrating an understanding of how the environment might be manipulated in order for a specific task to be completed. These concepts are encapsulated within the NCPE, which for KS3 has recently been revised (QCA, 2007), and for KS2 a revised NCPE is due to be implemented in 2011 (Qualifications and Curriculum Development Agency (QCDA), 2009). These revised curricula promote flexibility of teaching and have removed some prescription in the way in which PE is taught, however, the curriculum remains targeted at nurturing a child's physical literacy through physical education.

The NCPE (DfES/QCA, 1999; Qualifications and Curriculum Authority (QCA, 2007) provides a framework for PE teachers to teach children how to benefit from physical activity. It states that PE provides opportunities for children to be creative, competitive and promotes healthy lifestyles. The NCPE adheres to the National Curriculum Inclusion Statement, allowing teachers to modify the ways in which PE is taught, so that the needs of individual children can be met. Prior to the 2007 revision for KS3 (QCA, 2007), however, teachers were required to follow the programme of study set out in the NCPE (which is currently still relevant for KS2). The 6 activity 
areas from which KS2 teachers (and previously, KS3) are required to teach from are dance, games, gymnastics, swimming, athletics and outdoor and adventurous activities, with the aim for children to build knowledge, skills and understanding of the activities.

Penney and Chandler (2000), however, debate whether the placement of these activities within the curriculum detracts from what PE is about. They argue that PE is not about teaching children specific activities; rather that it is about teaching them specific skills and competencies through the activities. This is dependent on teachers interpreting the curriculum in a way which does not focus on the "sport" of PE, highlighted through success in learning how to perform in specific activities, but instead to highlight the ways in which necessary skills can be learned through the activities children do. In light of this, revisions of the secondary (KS3) curriculum in 2007 (QCA, 2007), were implemented in September 2008, and altered the guidance from which KS3 PE is taught. From 2008, it was determined that secondary PE would become less prescribed in terms of the activity categorisation, and more flexible, allowing for teachers to "personalise the curriculum, designing learning experiences to meet individual needs and engage all learners" (QCA, 2007:5). The primary (KS2) curriculum, however has remained unchanged, requiring teachers to teach from at least 5 of the 6 curriculum areas, of which games activities, dance and gymnastics are compulsory, although as stated previously, in 2011 , the new KS2 curriculum will be implemented following a similar design to the KS3 one, promoting flexibility of teaching. For special schools, however, this differs. Special schools are not bound by the NC, but rather, are disapplied, allowing them the freedom to develop their own curriculums relevant to the needs of the children they are teaching (DfES, 2006), yet several special schools aim to follow the NCPE as closely as possible to promote future inclusion of their pupils. 
Despite the differences in delivery for the two curricula, teachers are required to make judgements about pupil's performance at the end of KS 1,2 and 3, based on a series of levels which remain consistent throughout the key stages. As such, it is expected that, for example, by the end of KS3 (age 14), children will be achieving between a level 3 (level 4 in the 2007 revision) and level 7 (level 8 in the 2007 revision) in PE. This means that children should be able to, at a minimum, be able to

"Select and use skills, actions and ideas appropriately, applying them with co-ordination and control... understand tactics and composition by starting to vary how they respond... give reasons why warming up before an activity is important, and why physical activity is good for their health."

(DfES/QCA, 1999:43)

This highlights that the intended purpose of PE is for children to develop appropriate skills, understand strategies for moving within a specific environment, and finally to understand how this affects their health, rather than providing children with an opportunity to become physically fit in PE lessons. Thus, it is clear that the PE presents one primary purpose - to develop children's physical literacy (Whitehead, 2001). This is further emphasised within the NCPE which states the importance of PE in developing "pupils' physical competence and confidence, and their ability to use these to perform in a range of activities. It promotes physical skillfulness, physical development and a knowledge of the body in action" (DfES, 1999:15). Despite this, the ways in which these concepts are taught has become a debated topic within PE research (Penney and Chandler, 2000; Penney, 2002; Whitehead, 2001; Evans, 2004). 


\section{Physical Literacy versus Physical Fitness}

Researchers often argue that the nature and structure of the NCPE, and the activities within it serve to exclude rather than include children with SEN (Penney, 2002; Smith, 2004; Smith and Green, 2004; Smith and Thomas, 2006). In particular, they criticise the emphasis on competitive and team games within the NCPE, claiming that these are often unsuitable for children with SEN, and this is something teachers highlight as constraining for their practice (Smith and Green, 2004; Smith, 2004). Despite the constraint caused by the emphasis of team games in PE, Smith and Green (2004) report that often PE teachers are reluctant to give up this sporting tradition (Smith and Green, 2004), and therefore they, too, place focus on achieving and performing in traditional competitive sports. Teachers consequently report that including children with SEN fully into team games can prove difficult and unrealistic activities, as children are required to recognise and understand rules, as well as have awareness for positioning and tactics - something which some children with SEN find particularly difficult (Smith, 2004). These skills required of any activity, but more prominent in games activities (Mandigo and Holt, 2004), are what can be referred to as physical literacy. Whitehead (2001:136) argues that "physical literacy requires a holistic engagement that encompasses physical capacities embedded in perception, experience, memory, anticipation, and decision making."

As such, physical literacy relates to the capabilities and competencies required to be deemed successful in an activity (Killingbeck et al, 2007). It emphasises the education of children about their physicality, teaching them a deeper understanding of their own embodiment of movement, and they ways in which to use their bodies in a given environment. More than this, it relates to the embodiment of these notions in such a way as to understand the role of one's body and a consideration for how the body can be used in an environment to achieve a specified purpose. Therefore, physical literacy provides a theoretical framework from which to promote children's learning in the physical spaces in which they interact (Lee, 2004). In terms of PE, that purpose, 
as identified in the NCPE (QCA, 2007), is to understand the rules in different activities, to learn the specific skills necessary and to apply these skills and knowledge in such a way as to demonstrate that those skills and rules have been learned and can be applied creatively in a number of environments.

When notions of physical literacy are applied to inclusion, Penney (2002) argues that the NCPE does little to prompt inclusivity due to its focus on sport, performance, skills, knowledge and achievement. She states that this acts in the interest of only a minority of children who perform highly in these sporting areas (Penney, 2002; Smith, 2004). This, however, does not only apply to children with SEN. Jones and Cheetham (2001) agree with this. They argue that while the NCPE presents principle based around skill acquisition, decision making and performance, these core goals are not being realised, which has resulted in children misunderstanding the purpose of PE. Rather, it is disputed that PE for many children is perceived as a break from 'normal lessons' (Green, 1998), or an opportunity to build fitness (Jones and Cheetham, 2001; Evans, 2004). This is further demonstrated by Jones and Cheetham (2001), who provide empirical evidence to show that secondary school children perceive PE as health related exercise which bore no relevance to their out-of-school lives. This in essence implies that children do not understand the core aims of PE to nurture and help develop their sense of physicality. This further raises questions about whether the aims of the NCPE to develop physically literate children is being realised, particularly if children understand PE in terms of health benefits rather than skill and competency acquisition. This paper aims to explore the concepts of physical literacy versus physical fitness further. It is intended that by gaining insight into the perceptions of children about what they understand the purposes and benefits of PE to be, recommendations about developing notions of physical literacy within the curriculum and in teacher education can be made. Moreover, this paper explored the perceptions of a marginalised sample of children - those who have special educational needs, in order to 
recognise the ways in which these children conceive $P E$, as they are considered to have difficulty in acquiring and using the skills required and taught within some PE activities (Smith, 2004).

\section{Methodology}

\section{Design and Method Selection}

A qualitative phenomenological research design was employed in the research, allowing children to explore their experiences of PE and the meaning they placed on these experiences (Smith et al, 2009). Phenomenology encourages researchers to not stray from the context which is being researched and to stay true to the original meaning of the data, rather than reducing the data to a number of measurable, and controllable variables (Giorgi and Giorgi, 2008). It allows the participant to reflect on their experiences, therefore developing their own personal meaning or 'perception' related to that experience (Smith et al, 2009). Phenomenology is based on the concept of "intentionality", which explores the relatedness of human consciousness to an 'object' (Crotty, 2009; Smith et al, 2009). Intentionality is simply defined by Smith et al (2009:13) as "the relationship between the process occurring in consciousness and the object of attention for that process... experience or consciousness is always consciousness of something - seeing is seeing of something, remembering is remembering of something, judging is judging of something" [emphasis added]. As such, this paper examines the conscious meaning children with SEN place on their participation in PE lessons, by focusing on their narrative experiences of the activities they participate in, their perceptions of the purpose and benefits of $P E$, and by reflecting on their personal experiences of PE.

As such, informal focus groups and semi-structured interviews were conducted with children in each school. The use of qualitative methods allowed children to articulate and explore their perspectives surrounding PE openly. Moreover, a participatory approach was adopted in the 
focus groups, which allowed children the opportunity to explore their perceptions using nonverbal methods (Woodhead and Faulkner, 2000), such as through drawing and worksheet based activities.

\section{Informants}

This article presents some of the findings from a larger phenomenological study which took place in six schools in one North West County in England. These schools included two mainstream secondary schools, two mainstream primary schools (including a SEN base unit attached to one primary school), one special school, and one hospital school. In total 30 children with a variety of different SEN took part in the research, including 14 females and 16 males. The mean age of the children was 10.3 years. The participants ranged in ability and type of SEN, but were all registered on the schools SEN register at school action (SA) (27\%, $n=7)$, school action plus $(\mathrm{SA}+)(40 \%, n=12)$ or statemented $(37 \%, n=11)$. Using the categories outlined in the SEN Code of Practice (DfES, 2001a) for defining SEN, the majority of the children who participated in this study had cognition and learning needs $(73 \%, n=22)$. However, it is worth noting that several children did not only fit into this category of SEN, but had other needs as well. SEN are difficult to categorise using distinct categories due to the incidence of co-morbidity, and as such tend to be placed on a concept of a spectrum of needs (Vickerman, 2007b). As such, Table 1 attempts to illustrate the co-morbidity of difficulties experienced by children in this study, based on the information available on the SEN register at each school.

[insert table 1] 


\section{Focus Groups and Interviews}

Six focus groups were conducted and 24 children with SEN across these schools took part. Prior to starting the focus groups at each school, participants were reminded of their right to withdraw from the research and informed that the intention of the focus group was to find out about their experiences of $\mathrm{PE}$, and their perceptions about how they thought PE could be improved for them. They were also informed that all data collected would remain confidential, and that their teachers would not be informed about what they had discussed. Participants were given the opportunity to ask questions relating to the research to ease any concerns they might have. This was in line with ethical guidelines set out by BERA (2004), and acted as a starting platform to build trust between participants and the researcher (Woodhead and Faulkner, 2000).

Focus groups were participatory and as such participants were asked how they would like to partake in the focus group. This was done to empower participants to make decisions about how to express and discuss their experiences (O'Kane, 2000). Participants were provided with options about how to complete the focus group, ranging from researcher controlled to student led. This allowed participants to decide which method they felt suited their needs best (DfES, 2003), and as such took into account the differing needs of participants at different schools.

Once the focus group had begun, participants were given freedom to interpret and direct discussion, and were presented with activities to allow them to engage with their experiences. This also allowed varied communication methods, providing participants with the scope to present their views in written, spoken and other more visual forms. 
Following the focus groups, interviews were held with two children in each school, except for the hospital school, where all four participants were interviewed. The interviews were used to elicit more personal reflections on experiences of PE. In total 18 one-to-one, interviews took place, which included 10 with male participants (55\%), and 8 with female participants (45\%).

A semi-structured approach to interviewing (Robson, 2006) was adopted in order to allow children the opportunity to explore their perspectives and experiences in a less formal manner, providing the researcher the opportunity to facilitate this exploration in order to draw out richer data. While an informal interview would have been more beneficial for these purposes (Robson, 2006), Scott (2000) notes that children as interviewees may require more guidance in responding to interview questions, and as such an informal interview was deemed unsuitable for the purposes of the research. Nevertheless, all interview items were open-ended, and in most cases allowed for conversation to be generated between the interviewer and interviewee. This was done to redress the power balance in the interview setting (Cohen et al, 2007), with the intention of making the child feel more comfortable.

All interviews took place at the child's school. Scott (2000) states that in school settings, child participants might be biased by the presence of peers or teachers. In order to overcome this, all children were interviewed away from their peers and teachers in a private room or empty classroom on school premises. Children were informed prior to starting the interview that all responses would be kept in the strictest of confidence and that only the researcher would listen to any recordings made. They were reminded that their teachers would not be told what they said, and that the intention of the interview was to find out their personal feelings about and experiences of PE at school. 
As with all interviewing techniques, interviewing children runs the risk of social-desirability biases. However, Scott (2000) notes that social desirability bias tends to be more prevalent in adults, making it an "adultcentric" concept. As such, this, while still being of concern, was not thought to disadvantage the data to a large extent. Furthermore, careful questioning, and the acceptance of "I don't know" responses, limited the chance of children feeling pressured to just give any response. In addition to this, children's responses were taken at face value. Scott (2000) claims that in doing this, data is made more reliable, as research has proven that children give highly reliable testimonies. Validity was generated in a similar fashion, by ensuring that the direction of conversation throughout the interview was relevant to the topic at hand.

\section{Data Analysis}

Data was analysed thematically interpretive phenomenological analysis (IPA) (Smith et al, 2009). Smith et al (2009) argue that IPA in its nature does not pertain to one specific analysis strategy, but rather is flexible, presenting an approach which focuses analytic attention on the participants, in an attempt to make sense of their experiences. As such, in analysing the data from this study, great attention was paid to understanding the meaning participants placed on their own experiences as a means of addressing their perceptions of PE, but focussed upon their own explanations and descriptions, provided through a flexible research approach. Flexibility in the methodological approach to this research was considered to be more conducive to meeting the specific needs of the child participants, and is considered necessary when researching with children, particularly those from marginalised groups (Alderson, 2000).

The stages followed in analysing the data were as follows:

- Stage 1: Reflective data collection

- Stage 2: Transcription

- Stage 3: Understanding the data 
- Stage 4: Theme development

\section{Stage 1: Reflective data collection}

The research process as a whole was reflective. All processes involved in the data collection were evaluated and reflected upon throughout the study. To aid this, field notes, in the form of a research journal were kept. Notes were taken after each interview and focus group, and key points arising from the data were noted down alongside any situational factors thought to have influenced responses, for example, participant attention, changes in interview/ focus group format, environmental factors. In doing this, opportunity to reflect upon the research design was embraced. This resulted in continual evaluation of the methods.

Moreover, reflecting on the data directly after each interview and focus group, allowed for initial ideas about themes and key points to be drawn out. These were noted down, and formed preliminary ideas about findings. Smith et al (2009:82) state that it is important for phenomenological researchers to enter "a phase of active engagement with the data", and through the research journal, it is felt that re-connection with the participant via the journal ensured that any contextual meaning was not lost in the analysis process.

\section{Stage 2: Transcription}

Following the completion of the data collection, all focus groups and interviews were transcribed verbatim. On completion of this, transcripts were read, whilst listening to original recordings to ensure the accurateness of the transcriptions. All transcriptions were then grouped by school type (primary, secondary, special and hospital school), and re-read together as groups, in order to gain an understanding of the kinds of data collected in relation to the context in which it was collected. The data was at this point deemed ready for analysis. 


\section{Stage 3: Understanding the Data}

To begin understanding and interpreting the data in relation to the research questions, all interview transcripts were summarised. This involved reducing down the verbatim transcripts into more understandable narratives. The participants own words were used in the summaries, and every effort was made to not paraphrase responses. As such, summaries reported findings in an understandable and readable format, allowing for findings to be understood fully, without the messiness of verbatim transcripts. Notes were taken during this process about the potential themes (Smith et al, 2009), and summaries were grouped and read in terms of the type of school the participants attended (primary, secondary, special and hospital), in order to understand the similarities and differences in PE between the different school types.

\section{Stage 4: Theme Development}

Once the data had been accurately transcribed, summarised and understood, thematic analysis was undertaken. Separate analysis took place for special, mainstream, special and the hospital schools, using pre-determined categories, based on the themes covered in the interview questions (developed from previous literature and the pilot study findings). These categories related to the PE lessons and activities outside of school, perceptions of PE teachers and classmates, perceptions of the self, difference and empowerment. Responses were grouped by category for each type of school, allowing for similarities and differences in responses from different participants in the same type of school to be ascertained, as well as highlighting emerging themes arising from within the pre-determined categories.

The interview data were triangulated with the focus group data (Robson, 2006). The focus group data were analysed using the same categorisation system. This was then cross referenced with 
the interview data to determine reliability in thematic analysis. In undertaking this analysis process, four key themes were developed from the data. Findings from one of those themes, 'understanding PE', are presented here.

\section{Findings}

This paper presents findings from the core theme, 'understanding PE'. Within both interviews and focus groups, the children with SEN in this study were asked to explore ideas about why they do PE and what they perceived the benefits of PE to be. These questions were asked in order to assess children's understanding about the purpose of PE as a means of gaining further insight into their experiences. The theme, 'understanding PE', was through the analysis of two interrelated sub-themes:

- PE: tool for getting fit

- PE: prevention against getting fat

Table 2 presents some examples of the data which pertain to these to these two sub themes.

[insert table 2]

The table above demonstrates some of the data collected from the children with SEN in this study. What was apparent was that for all of the children who responded to the question "why do you do PE?" the main reason, from their perspective was that PE had the purpose of getting them fit. Statements such as "cos you can stay fit"; "to keep us fit", "fitness, strength, stamina", "because it's like, good exercise", were commonplace, standard responses to the question. When asked to explore this further, it was evident that there was an interrelated theme developing - children perceive PE as a tool to get fit and that there is a relationship between 
getting fit and not getting fat. As such, children frequently made reference to factors relating to physical fitness, such as growing muscles, increasing energy, and losing weight, as demonstrated in the data excerpts presented in Table 2. The statements indicate that the children with SEN in this study tended to believe the main benefits of PE were to get fit, lose weight, and increase energy. It is worth noting that this was true for children in each school and of each type of SEN. It was therefore evident that these perceptions about the benefits and purposes of PE were not limited to any group of children in this study, but, rather, were representative of the sample as a whole. The comments all related to PE as a method for improving physical fitness.

In exploring the reasons why children perceived physical fitness to be a main aim and benefit of PE, weight loss, and the reduction of fat seemed to be a main concern for several children. In analysing the data, it was evident that the children with SEN in this study understood the relationship between diet, exercise and fitness. In particular, children were able to articulate their understanding that excess food, and too little exercise would result in weight gain. Moreover, weight control and reducing the likelihood of becoming "fat" appeared to be a main influence on children's participation in PE.

In addition to this, it is possible that some PE teachers are overemphasising aspects of physical fitness in PE. There was evidence within the study of perceived discrimination against children who might be overweight, which resulted in unfavourable experiences for the child and decreased participation in PE. This particular issue was raised by two girls in this study who stated they were bullied by their PE teachers for being fat. This is illustrated below: 
CG: I didn't really do PE [in mainstream school], cos the PE teacher used to bully me, used to call me fat and that to make me feel bad, and that happened at primary school as well.

[Interview with CG, School G] LG: The teachers were nasty and because of me size very nasty about that as well, erm and they sort of overworked ya, that kind of thing like they worked you over what your limits are.

[Interview with LG, School G]

Both of these participants indicated that they were discriminated against by their teachers for being overweight, and in both cases, attributed their movement to the hospital school to their experiences of PE in the mainstream schools. What is clear for both of these participants was that they perceived their teachers to be concerned with their size and therefore, both girls limited the amount of time they spent in PE to reduce their feelings of insecurity and embarrassment around their PE teachers. As such, it is evident that an over-emphasis on weight could be detrimental to the experiences of children, not just those with SEN, in PE.

\section{Discussion}

The findings from this study showed that children with SEN perceived that the main purpose of PE was to increase their fitness. This is supported by Kristen et al (2002), who also found that children with SEN determine one of the benefits of PE to be in the strengthening of their physique. Similarly, Jones and Cheetham, (2001) found that the children in their study perceived PE as a method for building fitness. However, few children discussed the role of PE in developing new skills and learning about physicality (Kristen et al, 2002), or related what they 
learnt in PE to their out-of-school lives (Jones and Cheetham, 2001) - key components of physical literacy (Whitehead, 2001, 2005). According to Whitehead (2005):

"An individual who is physically literate moves with poise, economy and confidence in a wide variety of physically challenging situations. Furthermore the individual is perceptive in 'reading' all aspects of the physical environment, anticipating movement needs or possibilities and responding appropriately to these, with intelligence and imagination".

Whitehead (2005:5)

While it is understandable that this definition might be difficult for school-aged children to grasp, it was apparent notions of physical literacy - skill development, creativity, knowing the environment (Whitehead and Murdoch, 2006); were rarely accounted for by the children in this study. Rather, their understanding about why they participated in PE, and its benefits, tended to encapsulate constructs surrounding physical fitness (Evans 2004). As such, in terms of the NCPE (DfES/QCA, 1999; QCA, 2007c), it was clear that the children were not aware of, or did not comprehend the purpose of PE in improving their physical literacy, or becoming physically educated (Evans, 2004). The idea that children are unaware of the education aspects of PE was further highlighted in one focus group in this study. A child in School B asked the researcher "What does PE stand for?" to which he was told "Physical Education is what PE stands for". The child's response to this was one of shock, when he exclaimed "What? Physical Education!" This indicates that children are perhaps not aware of the true meaning and purpose of $P E$, in terms of its role in educating children about notions of physicality, which grounded in physical literacy (Whitehead, 2001; Evans, 2004; Whitehead and Murdoch, 2006; Killingbeck et al, 2007). For these children, it was apparent that their physical education was less about their learning, skill development and competency building (Penney and Chandler, 2002, Lee, 2004; 
Killingbeck et al, 2007), and more about physical activity. The children with SEN perceived PE as a lesson for becoming fit. This might be in some way related to the argument put forward by Smith and Green(2004) that PE teachers are often unwilling to give up the 'sporting tradition' and therefore favour activities which require extensive skills and competencies, such as competitive games activities. Perhaps for children with SEN who are likely to find games activities - which tend to be more prevalent in PE (Smith, 2004; Coates and Vickerman, 2010) more difficult, PE teachers are shying away from teaching the competency based aspects of such activities in favour of highlighting the fitness aspects which most children will grasp. Alternatively, it is possible that these findings do not only relate to children with SEN - Jones and Cheetham (2001) found similar results, yet the children in their study did not have SEN. Evans (2004) argument that constructs surrounding the notion of education in PE have been somewhat lost within initial teacher training (ITT) could go some way to explain this. He states that "talk of 'education' and 'educability' [has been driven] from the language of PE" in the interests of health and fitness (Evans, 2004:97). As such, it could be argued that the conception of these children that PE is only about physical fitness, could in fact be constructed through their teachers, and society, who, according to Evans (2004) may misconstrue the purpose of PE themselves, in place of a prominent values for physical health and fitness.

Alternatively, it is also possible that these children are being taught skills and competencies relating to developing their physical literacy, but this is being misinterpreted by children, and rather perceptions relating to physical fitness are more prominent. This might be related to societal influences on children, for example healthy living campaigns. Ideas surrounding physical fitness and physical health are emphasised physical activity and healthy living campaigns set up by government departments, which engage children in concepts surrounding physical fitness and health, and particularly obesity (Evans, 2003, Evans et al, 2004). An 
example of this in current media is the Change4Life campaign set up by the National Health Service (NHS), which aims to raise awareness amongst children and families to eat healthily and exercise more frequently in order to "live longer" (NHS, 2010: online). Moreover, the campaign states that "9 out of 10 kids today could grow up with dangerous amounts of fat in their bodies" (NHS, 2010: online). The media attention drawn by such campaigns could further influence the ways in which children understand and conceptualise ideas surrounding PE and exercise, which could contribute to their understanding that $\mathrm{PE}$, and the physical activity involved within $\mathrm{PE}$, is about exercising and becoming physically fit.

Moreover, weight control and reducing the likelihood of becoming "fat" appeared to be a main influence on children's participation in PE, and this seems to reflect the ideas circulated in healthy living campaigns such as Change4Life (NHS, 2010). Evans (2003) further argues that healthy eating aims have become more widespread within the teaching of PE, and that teachers are being encouraged to include this as part of the PE curriculum, and this is clearly indicated through the perceptions of the children with SEN in this study who state that their understanding of PE is one which encapsulates healthy eating and physical fitness. Yet, Evans $(2003,2004)$ argues that in raising awareness of obesity and healthy lifestyles through PE, educators are ignoring the other, fundamental aims of PE as a method for educating children about their physicality.

In addition to this, it is possible that, in a bid to decrease obesity numbers in the UK (Evans, 2003) through awareness-raising in PE, some teachers are taking this a step further, and discriminating against children who are considered to be overweight. Evidence from this study demonstrated that some children felt discriminated against by their PE teachers, not because of having SEN, but due to their weight. This resulted in unfavourable experiences for the child and 
decreased participation in PE. Evans (2003) supports this argument, stating that constructs surrounding obesity and being overweight result in perceptions that these are "very bad things" (Evans, 2003: 94). Moreover, in understanding the relationship this has with PE, and children's perceptions that without PE they will become "fat", Evans et al (2004) argue these constructs can lead to children striving to fit in with the norms of a slim society. It appears, from the findings of this study, that in PE embracing notions of fitness and weight loss, over concepts surrounding physical literacy and children's learning, children are not necessarily experiencing the fundamental core outcomes that PE lessons should promote, such as self-confidence, esteem and competence of movement (Whitehead, 2001; Evans, 2003; Evans et al, 2004). Moreover, in examining the current findings, it is evident that this has resulted in children misunderstanding some of the core aims of PE (DfES/ QCA, 1999; QCA, 2007) in developing their physical literacy, promoting their learning and educating them about their physicality. Alternatively, it is apparent that children's conceptions about PE are constructed around physical fitness, with the emphasis of health-related, rather than learning-related outcomes.

\section{Conclusions and Implications}

This article set out to determine how children with SEN understood the purpose and benefits of $\mathrm{PE}$, in order to provide some insight into how they might experience PE. It was found that the children with SEN in this study all perceived PE as a method for improving physical fitness, with its main benefit being weight loss and reduced risk of becoming fat. This was conceptualised in terms of physical literacy versus physical fitness (Whitehead, 2001; Evans 2004), where it was determined that aims surrounding the development of physically literate children was being overlooked in favour of producing physically fit children, reducing obesity and raising awareness about healthy eating (Evans, 2003; Evans et al, 2004). It was evident, however, through the findings of this study, and the work of Evans (2003), and Evans et al (2004), that approaching 
PE solely in terms of weight management and fitness was detrimental to children. Nevertheless, it is important to highlight that the perspectives presented here are from a small sample of children, all of whom have SEN. It is possible, therefore that these perceptions are limited to this group, or, more so, that had the study examined the perceptions of children who do not have SEN; different results might have been discovered. As such, this study might have been strengthened by an examination of the perception of non-SEN children, or perhaps by interviewing the children's PE teachers in order to gain an understanding of how and what they teach, as well as their attitudes towards physical literacy and physical fitness; and how these might differ to the perceptions of the children in their classes. Therefore, future research might aim to examine the perceptions of non-SEN children, PE teachers, and perhaps even parents in order to understand their conceptions surrounding the purpose of physical education, and their understanding of both physical literacy and physical fitness. This may contribute towards a greater understanding of how children's perceptions and attitudes about PE are constructed and indicate whether their views are in some way influenced by those of the adults around them.

Nevertheless, in understanding these perceptions, it is anticipated that insight into the experiences of children with SEN can be addressed, through thorough analysis of their perceptions surrounding their lived experiences of PE lessons. This has also brought to light the depth to which social understanding surrounding obesity, weight, exercise and diet have become deep-rooted in the perceptions of children with SEN in this study when understanding why they do PE. This needs to be readdressed, in order to limit the development of negative self-perceptions surrounding food and exercise, which according to Evans (2003) can damage the health of children in schools. It is evident, as illustrated in this study; that an overemphasis on weight, can lead to detrimental effects on participation in PE. As such, it is recommended that government educationalists address this, ensuring it is clear in both policy and the 
curriculum, that PE is not only about getting children fit (Evans, 2003, Evans, 2004), but that it is about making children aware of how they can use their bodies, teaching them the skills and competencies to become physically literate (Whitehead, 2001; Lee 2004; Killingbeck et al, 2007). In doing this, teachers should also address the ways in which they approach their teaching, ensuring they teach inclusively and without discrimination, in order to ensure children, both those with, and without SEN, leave school educated about their own physicality and needs; rather than the socially constructed perception that they should use exercise and food in order to control weight (Evans et al, 2004).

It is recommended that concepts surrounding physical literacy outcomes need to be factored more forcefully into the PE curriculum and embraced by teachers. This could be achieved by ensuring teachers are aware of the core goals of the NCPE in its aim to improve children's physicality, and their knowledge of how to use their bodies, rather than focusing on fitness (Evans, 2004) and sport (Smith, 2004). As such, it is suggested that ITT and continued professional development providers embrace notions of physical literacy and make current and future teachers aware of the implications of teaching PE for fitness, rather than teaching PE to physically educate children. In doing this, knowledge transfer to children should ensure that they are educated about how they can use their bodies and learn about their environment, so that PE becomes more about the education (Evans, 2004) of physicality, rather than about producing physically fit children. 


\section{References:}

Alderson, P. (2000) Children as Researchers: The effects of Participation Rights on Research Methodology, in Christenson, P. and James, A., Research with Children: Perspectives and Practices, Flamer Press: London

Coates, J. and Vickerman, P (2010) Empowering Children with Special Educational Needs to Speak Up: Experiences of Inclusive Physical Education, Disability and Rehabilitation, 32 (18), $1517-1526$

Crotty, M. (2009) The Foundations of Social Research: Meaning and Perspectives in the Research Process, London: Sage

Department for Education and Skills (2001) Special Educational Needs Code of Practice, HMSO, London

Department for Education and Skills (2006) Disapplication of the National Curriculum (Revised), Nottingham: HMSO

Department for Education and Skills / Qualifications and Curriculum Authority (1999) The National Curriculum: Handbook for Secondary Teachers in England, London: QCA

Evans, J. (2003) Physical Education and Health: a Polemic or "Let Them Eat Cake!", European Physical Education Review, 9(1):87-101

Evans, J (2004) Making a difference? Education and 'ability' in physical education, in European Physical Education Review, 10(1), 95 - 108

Evans, J.; Rich, E. and Davies, B. (2004) The Emperor's New Clothes: Fat, Thin, and Overweight. The Social Fabrication of Risk and III Health, Journal of Teaching in Physical Education, 23, 372-391

Giorgi, A. and Giorgi, B. (2008) Phenomenology, in Smith, J. Qualitative Psychology: A practical guide to Research Methodology, London: Sage 
Green, K. (1998) Philosophies, ideologies and the practice of physical education, Sport, Education and Society, 3, 125-143

Jones, R. and Cheetham, R. (2001) Physical education in the national curriculum: its purpose and meaning for final year secondary school students, European Journal of Physical Education, 6, 81-101.

Killingbeck, M.; Bowler, M.; Golding, D.; Gammon, P. (2007) Physical Education and Physical Literacy, Physical Education Matters, 2 (2), 20-24

Kristen, L.; Partiksson, G.; and Fridlund, B. (2002) Conceptions of Children and Adolescents with Physical Disabilities about their Participation in a Sports Programme, European Physical Education Review, 8(2), $139-156$

Lee, M. J. (2004) Values in Physical Education and Sport: A Conflict of Interests, British Journal of Teaching Physical Education, 35 (1), 6-8

Mandigo, J. And Holt, N. (2007) Reading the Game: Introducing the Notion of Games Literacy, Physical and Health Education, 70 (3), 4 -10

NHS (2010) Change4Life, available at http://www.nhs.uk/change4life, last accessed 12/09/2010

Penney, D. (2002) Equality, equity and inclusion in physical education and school sport, in: Laker, A. (Eds), The Sociology of sport and Physical Education, London: Routledge Falmer 
Penney, D. and Chandler, T. (2000) Physical Education: What Future(s)? Sport, Education and Society, 5(1), $71-87$

Qualifications and Curriculum Authority (2007) Physical Education: Programme of study for key stage 3 and attainment target, London: QCA

Qualifications and Curriculum Authority (2007) The New Secondary Curriculum: What has Changed and Why?, London: QCA

Qualifications and Curriculum Development Agency (QCDA) (2009) Primary curriculum Review: Curriculum reform consultation report to the DCSF, available at http://publications.teachernet.gov.uk/eOrderingDownload/QCDA-09-4355.pdf, last accessed 03/09/2010

Smith, A. (2004) The Inclusion of Pupils with Special education Needs in Secondary School Physical Education, Physical Education and Sport Pedagogy, 9(1) 37 - 54

Smith, A. \& Green, K. (2004) Including pupils with special educational needs in secondary school physical education: a sociological analysis of teachers' views, British Journal of Sociology of Education, 25(5), 593-608.

Smith, A. and Thomas, N. (2006) Including pupils with Special Educational Needs and Disabilities in National Curriculum Physical Education: a brief review; European Journal of Special Needs Education, Volume 21(1), 69 - 83

Smith, J.; Flowers, P. and Larkin, M (2009) Interpretive Phenomenological Analysis: Theory, Method and Research, London: Sage

Vickerman, P. (2007b) Teaching Physical Education to Children with Special Educational Needs, Oxon: Routledge

Whitehead, M. (2001) The Concept of Physical Literacy, Physical Education and Sport Pedagogy, 6(2), $127-138$ 
Whitehead, M. (2005) PE for Today's Children, presented at the Primary Physical Education Conference, Roehampton, July 2005

Whitehead, M. And Murdoch, E. (2006) Physical Literacy and Physical Education: Conceptual Mapping, Physical Education Matters, 1(1), 6 - 9

Woodhead, M. and Faulkner, D. (2000) Subjects, Objects or Participants? Dilemmas of Psychological Research with children, in Christenson, P. and James, A., Research with Children: Perspectives and Practices, Flamer Press: London 
Table 1: Participant SEN Overview

\begin{tabular}{|l|l|}
\hline Number of Participants & 30 \\
\hline Average Age & 10.3 \\
\hline$\%$ at SA & 23 \\
\hline$\%$ at SA+ & 40 \\
\hline$\%$ Statemented & 37 \\
\hline$\%$ Communication and interaction needs & 10 \\
\hline \% Cognition and learning needs & 76 \\
\hline $\begin{array}{l}\text { Emotional behavioural, and social } \\
\text { development needs }\end{array}$ & 17 \\
\hline$\%$ Sensory and/or physical needs & 17 \\
\hline$\%$ Medical Conditions & 13 \\
\hline
\end{tabular}

Table 2: Children's perceptions about the purposes and benefits of PE

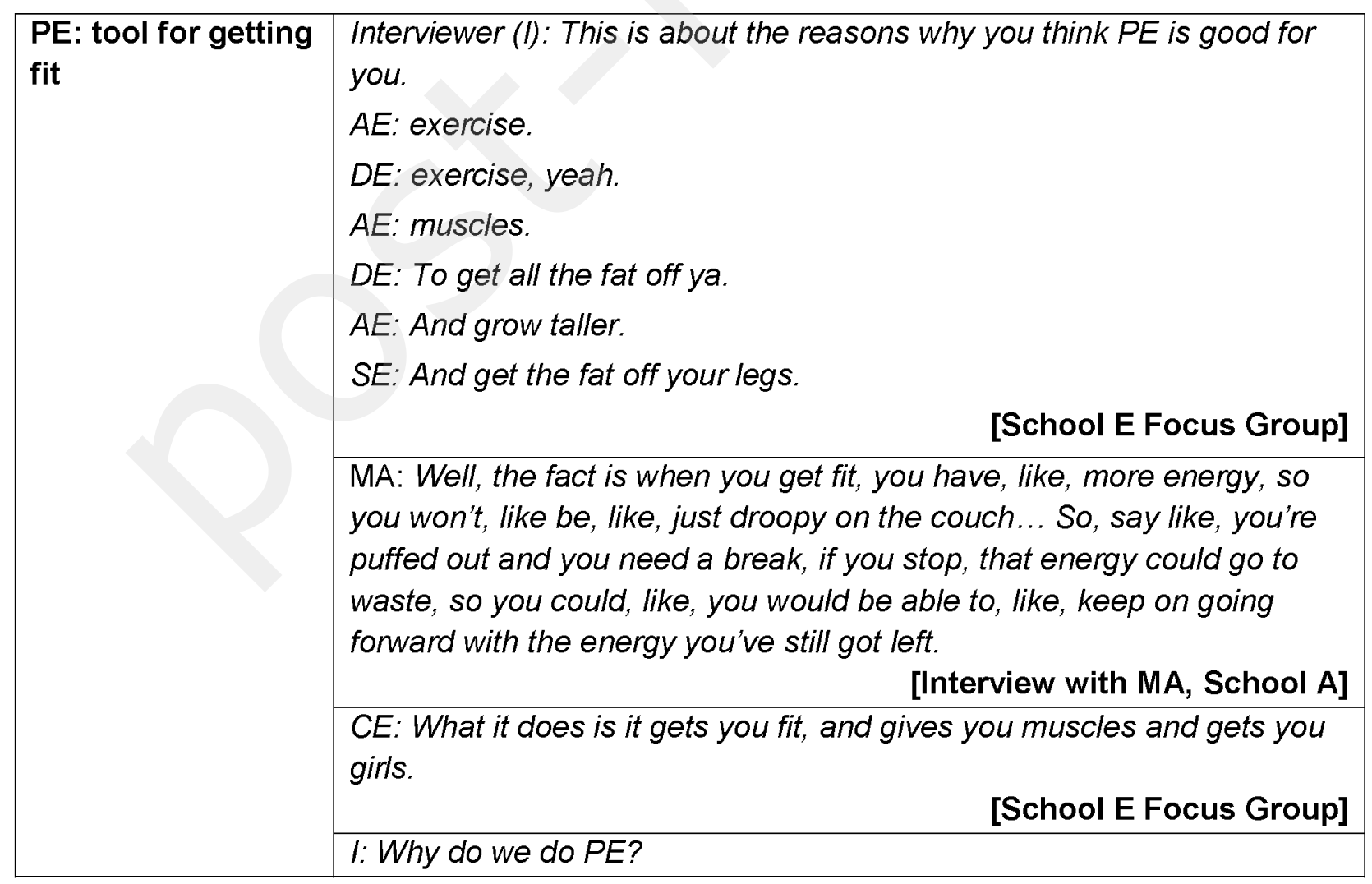




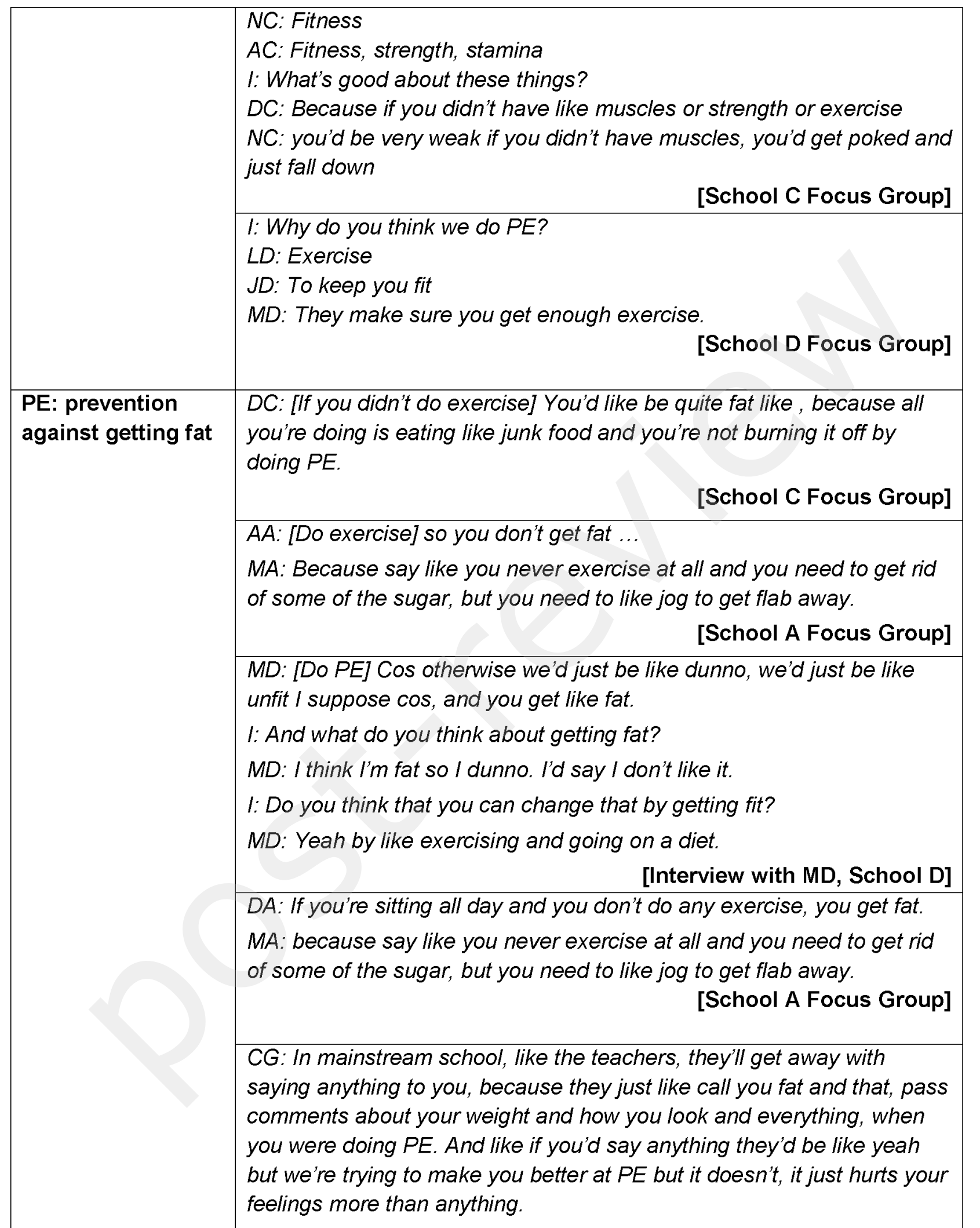

[Interview with CG, School G] 